\title{
Nutrition and physical activity environments in primary schools in Poland - COSI study
}

\author{
Magdalena Korzycka ${ }^{1, A-D \oplus}$, Maria Jodkowska ${ }^{1, A-D \oplus}{ }^{\circ}$, Anna Oblacińska ${ }^{1, D-E \oplus}$, Anna Fijałkowska ${ }^{1, E-F} \oplus$ \\ ${ }^{1}$ Institute of Mother and Child, Warsaw, Poland \\ A - Research concept and design, B - Collection and/or assembly of data, C - Data analysis and interpretation, \\ $D$ - Writing the article, E-Critical revision of the article, F- Final approval of the article
}

Korzycka M, Jodkowska M, Oblacińska A, Fijałkowska A. Nutrition and physical activity environments in primary schools in Poland - COS study. Ann Agric Environ Med. 2020; 27(4): 605-612. doi: 10.26444/aaem/114223

\begin{abstract}
Introduction. Schools are important settings for the promotion of healthy diet and sufficient physical activity to prevent civilisation diseases related to lifestyle.

Objective. To describe school physical activity and nutrition environment in elementary schools in Poland, and to asses differences in school physical activity and nutrition environments, depending on school location and size.

Materials and method. Data was used from the World Health Organisation European Childhood Obesity Surveillance Initiative (COSI) conducted in 2016 in 135 Polish schools. Logistic regression was used to asses association between the location and individual school environment indicator. On the basis of answers to 20 questions about school physical activity and nutrition environment, a positive school environmental assessment index was compiled.

Results. Large, urban schools were characterised by a significantly greater availability of sweet snacks, whereas flavoured milk with added sugar was more often available in small and rural schools. The univariate logistics analysis parameters showed that an urban-rural location had a significant association for the availability of an indoor gym and existence of a canteen and a shop. Analysing the positive schools environmental assessment index, there were no statistically significant differences in mean values due to location, but statistically significant differences were found depending on the school size, with the highest level in large schools and the lowest in small schools.

Conclusions. The factor which adversely differentiates the school environment in terms of healthy nutrition and physical activity is primarily the school size, and then the school location. Systemic and social solutions should aim at reducing the small school "exclusion syndrome", both in rural and in urban areas, also with regard to infrastructure and availability of conditions conducive to healthy nutrition and physical activity.
\end{abstract}

\section{Key words}

primary school, school activity environment, school physical activity environment

\section{INTRODUCTION}

Schools are an important environment where children and youths spend large amounts of time, and have a significant impact on their health. Schools are not only an ideal setting for promoting life-long positive health behaviours, but also engage in broadly understood prevention of health problems, including civilisation diseases related to lifestyle. Numerous authorities from the field of education, public health, and medicine suggest that schools need to expand their role to counteract the spread of lifestyle diseases, particular obesity [1].

The focus is first of all on the physical activity (PA) of pupils at school. Regular physical activity during physical education (PE) classes, exercises during the recess and during extracurricular activities at school contribute to the appropriate physical development of pupils, have a beneficial impact on their social and emotional development and offer a possibility to acquire new motor skills, needed to engage in lifelong PA [2]. Regular physical exercises play an essential role in maintaining an appropriate body weight and thus reduce the risk of obesity and related diseases. In order to

Address for correspondence: Magdalena Korzycka, Institute of Mother and Child, Poland

E-mail: magdalena.korzycka@imid.med.pl

Received: 17.07.2019; accepted: 13.09.2019; first published: 13.12.2019 ensure that pupils can have an appropriate dose of physical activity at school, the school environment undoubtedly must be equipped with appropriate elements, including first of all the school infrastructure with a well-equipped and aesthetic indoor gym and an outdoor playground area. Highly qualified PE teachers at all school levels also play an important role [3].

As in the case of the PA of pupils, schools play a similar role in terms of appropriate nutrition, and seem to be a promising place for intervention aimed at improving the children's diets. They provide an excellent opportunity to influence the children's choices at the decisive moment for development of nutritional behaviour $[4,5]$. It is all the more practically important, since a considerable part of total daily energy is consumed at school [6].

Children spend an increasingly long time at school, 4-8 hours a day, on average, and according to the principles of healthy nutrition, they should have a meal every 3-4 hours. Regular consumption of healthy foods, also at school, has a beneficial impact on the child's welfare, improving learning capacity, leading to better school achievements, and contributing to shaping a healthy eating habits for life. A Lithuanian study has shown that factors of dietary behaviour, such as unhealthy food and proteins, were significantly positively associated with BMI in children, while consumption of plant-based, dairy and confectionery items was significantly negatively associated with BMI [7]. 
Vegetables and fruits are an important component of a healthy diet. Research has shown that regular consumption of vegetables and fruits in an appropriate amount prevents cardiovascular diseases and some types of cancer, and helps maintain an appropriate body weight $[8,9]$. The availability of healthy food products and appropriate nutrition should be a priority in every school [10]. The schools' offer with respect to school nutrition environment should focus on the availability of healthy food products, such as fruits, vegetables, milk, and on providing healthy meals. An important role in this regard is played by school canteens, shops and cafeterias, as well as food vending machines, if they are located within the school premises and if they offer healthy snacks. In Poland, a Regulation of the Minister of Health of 28 August 2015 , shaped the range of products available in schools [11]. It specified the requirements to be met by food products sold and used as part of mass catering in schools. The new regulation was aimed at making it easier for kindergartens, schools and childcare facilities to implement measures allowing the shaping of proper eating habits among children and adolescents.This regulation was repealed and currently the Regulation of 26 July 2016 is in force [12].

\section{OBJECTIVES}

The aims of this study were to describe school physical activity and nutrition environments in elementary schools in Poland, and explore whether there are differences in school physical activity and nutrition environment, depending on school location and size.

\section{MATERIALS AND METHOD}

Data used in this analysis are based on the survey of the World Health Organisation European Childhood Obesity Surveillance Initiative (COSI) ${ }^{1}$. This study was conducted in 2016 in randomly selected 9 provinces in Poland: Dolnośląskie, Małopolskie, Mazowieckie, Opolskie, Podkarpackie, Podlaskie, Pomorskie, Śląskie and Wielkopolskie (Fig. 1), in a total of 37 counties. In the above-mentioned provinces, a total of 180 elementary schools were randomly selected as a representative the sample, in case some participants were to be excluded from the study. Provincial coordinators contacted the selected schools to obtain the consent of their principals, and in November 2016, they presented a final list of 135 schools from which the consent for the study was received. Urban schools accounted for $67 \%(\mathrm{~N}=91)$ of the analysed sample. The number of pupils in the randomly selected schools ranged from 48-1,158.

As part of the preparations for the implementation of the study in Poland, international cooperation was established with the WHO Country Office in Poland and with the WHO Regional Office in Copenhagen, Denmark, as well as with experts from Portugal and Italy (organisational meetings, substantive contribution to the training for coordinators). The methodology of the study was determined at that stage of the study and approved by international coordinators of the

${ }^{1}$ The study was financed under the National Health Programme Realization of the COSI survey in 2016-2017. (Agreement No 6/1/3.1.12/ NPZ/2016/106/1401).
COSI project in Europe. Consent for the study was obtained from the Bioethical Committee at the Institute of Mother and Child in Warsaw, Poland. A detailed description of the school selection was presented in a separate publication - The COSI Report [13].

Based on the Centres for Disease Control and Prevention definition, a healthy school nutrition environment provides students with nutritious and appealing foods and beverages, consistent and accurate messages about good nutrition, and ways to learn about and practice healthy eating throughout the time children spend on school grounds-including beforeand after-school. It includes: school meals, time for lunch, celebrations and rewards, food and beverage marketing [14]. In turn, the physical activity environment is a subset of a broadly defined physical environment which encompass both constructed and natural elements. The former environment includes all buildings, spaces, and objects created or modified by people. It includes homes, schools, classrooms, parks and recreation areas, greenways and transportation systems [15]. The scientific literature on this issue is increasing, therefore the measurement of constructed environments is the primary focus of this study.

The research tool used for assessing the school environment was a school survey questionnaire based on the model from the standardised international COSI protocol [16]. Questions in the survey were previously validated in a pilot study in schools, an important purpose of which was to check the reliability and validity of the questions. The questionnaire was completed mainly by the principals of schools $(60 \%)$ or designated persons, including school nurses (34\%), teachers and other school personnel (6\%). The school questionnaire included questions about the selected elements of school constructed environment structure, and activities of the school related to physical activity and nutrition.

Analysed variables and indicators. A total of 20 indicators (items) concerning the school physical activity and nutrition environmental characteristics were analysed.

School physical activity environment. The following questions from the survey questionnaire were used for analysing the school physical activity environment:

1. Does your school have outdoor playground area(s)? Available answers: yes, no.

2. Does your school have an indoor gym? Available answers: yes, no.

3. Are the children allowed to use outdoor playground areas outside school hours? Available answers: yes, no.

4. Are the children allowed to use the indoor gym outside school hours? Available answers: yes, no.

5. Does your school organize any sport/physical activities at least once a week for primary school children outside school hours? Available answers: yes, no.

6. In this current school year, for how much time each week does your school provide physical education lessons to the third grade pupils? Minutes per week.

School nutrition environment. The following questions from the survey questionnaire were used for studying the school nutrition environment:

1. Does your school have a canteen? Available answers: yes, no.

2. Does your school have a shop or cafeteria where foods or beverages can be purchased? Available answers: yes, no. 
3. Does your school have vending machines where children are allowed to purchase foods or beverages (other than water, fruit and vegetables)? Available answers: yes, no.

4. Is your school free from advertising and marketing of any energy-dense and nutrient-poor foods? Available answers: yes, no.

5. Which of the following kinds of foods or beverages can pupils obtain on the school premises: fruit, vegetables, water, milk, yoghurt, fruit juices with no added sugar, fruit juices containing added sugar, flavoured milk with added sugar, carbonated drinks containing added sugar, sweet snacks (sweet biscuits, candy bars, chocolate), savoury snacks (crisps, salted nuts)? Available answers: free, paid, not available.

For the purposes of this study, the answers of respondents concerning products and beverages were combined as follows: the answers "free" and "paid" mean "available".

School environmental assessment index. On the basis of answers to 20 questions about school physical activity and nutrition environment, the school environmental assessment index was compiled as follows: answers indicating a positive effect of the analysed variable on health received 1 point, otherwise no points were granted (0p.), e.g. an indoor gym within school premises -1 point, no indoor gym -0 points., availability of fruit 1 point, lack of availability 0 points. Regarding the question about the weekly duration of physical education lessons, an assumption was made that 3 lessons (135 minutes) or more meant the fulfilment of recommendation of the Ministry of National Education- 1 point, duration of lessons shorter than $135 \mathrm{~min}-0$ points [17].

Access to a vending machine selling products other than water and fruit/vegetables in school premises was considered a negative factor -0 points., and lack of a vending machine - 1 point; similarly access to sweet carbonated beverages - 0 points, lack of access -1 point. The cumulative school environment index was from $0-20$ points. The higher the result on the 20 -element scale, the healthier the school environment for pupils.

In this study, due to differences in schools in terms of their size, the schools were divided into 3 groups: small (1-159 pupils), medium (160-450 pupils) and large ( $\geq 451$ pupils).

Statistical analysis. Statistical analysis of the data used descriptive statistics: percentages, means and standard deviation. Differences between schools in terms of size and urban-rural location were analysed using the Chi-square test for cross tables, non-parametrical tests for means, the Mann-Whitney (M-W) test (comparison of 2 groups) and the Kruskal-Wallis (K-W) test (comparison of 3 groups).
The association between school location (independent variable, reference category - rural school) and school environment indicators (dependent variables) was analysed using logistic regression. Results of the univariate analysis were presented as odds ratios (OR) along with $95 \%$ confidence intervals (CI). The variable "school size" was then added to the analyses. A total of 40 logistic regression models were estimated, 2 for each factor related to school environment. The significance level of $\mathrm{p}<0.05$ was adopted in all analyses. SPSS v. 17.0 software was used.

\section{RESULTS}

School characteristics. In the analysed group of 135 schools, large schools (number of pupils $\geq 451$ ) represent the majority - over $43 \%$, and small schools ( $\leq 159$ pupils) were the least numerous $-16.3 \%$ In rural areas, medium schools - almost 60\% (number of pupils 160-450) and small schools prevailed, while urban areas were dominated by large schools, which accounted for almost two-thirds of schools, and by medium schools representing slightly over $30 \%$ of schools (Tab. 1).

Assessment of school physical activity environment. Table 2 presents selected school environment indicators related to physical activity, including the possibility for pupils to use an indoor gym, outdoor playground area within the school premises, a weekly number of physical education lessons, and the possibility to participate in sports activities outside school lessons, and their association with school size and location.

Almost 95\% of the analysed schools had indoor gyms. Statistically significant differences in access to indoor gyms were found depending on the school size, to the disadvantage of small schools and rural schools. In $70 \%$ of schools, pupils had access to an indoor gym, also outside school lessons. This possibility was available more often to children from medium and large schools and from urban schools. The majority of the analysed schools (93\%), both urban and rural, had outdoor playground areas. In over $92 \%$ of schools, the weekly number of physical education lessons amounted to 3 hours or more, more often in medium and large schools and in urban schools.

Univariate logistic analysis parameters, calculated for all analysed variables describing the school physical activity environment, showed that the urban-rural school location had a significant association only in the case of availability of an indoor gym $(\mathrm{OR}=14.21,1.65-122.08 ; \mathrm{p}=0.016)$. After entering the school size variable to the regression model, the urban-rural school location proved to be non-significant.

Table 1. Characteristics of schools in the COSI project by size and location

\begin{tabular}{|c|c|c|c|c|c|c|c|c|c|}
\hline \multirow[b]{2}{*}{ Size (No. of pupils) } & \multicolumn{2}{|c|}{ Total $(\mathrm{N}=135)$} & \multirow{2}{*}{$\begin{array}{c}\text { No. of pupils } \\
\bar{x} \\
(S D)\end{array}$} & \multicolumn{2}{|c|}{ Urban $(\mathrm{N}=91)$} & \multirow{2}{*}{$\begin{array}{c}\text { No. of pupils } \\
\bar{x} \\
(S D)\end{array}$} & \multicolumn{2}{|c|}{ Rural (N=44) } & \multirow{2}{*}{$\begin{array}{c}\text { No. of pupils } \\
\bar{x} \\
(S D)\end{array}$} \\
\hline & $N$ & $\%$ & & $n$ & $\%$ & & $n$ & $\%$ & \\
\hline $\begin{array}{l}\text { Medium } \\
(160-450)\end{array}$ & 54 & 40.0 & $\begin{array}{l}315.2 \\
(83.2)\end{array}$ & 28 & 30.8 & $\begin{array}{l}334.6 \\
(74.2)\end{array}$ & 26 & 59.2 & $\begin{array}{c}294 \\
(88.6)\end{array}$ \\
\hline
\end{tabular}


Table 2. Prevalence of selected school physical activity and nutrition environment indicators and their association with school size and location ( $\mathrm{N}=135$ schools)

\begin{tabular}{|c|c|c|c|c|c|c|c|c|c|c|c|}
\hline \multirow[b]{2}{*}{$\begin{array}{l}\text { Availability of the following at } \\
\text { school }\end{array}$} & \multirow[b]{2}{*}{ Total } & \multicolumn{4}{|c|}{ School size } & \multicolumn{2}{|c|}{ School location } & \multicolumn{4}{|c|}{ Result of logistic regression } \\
\hline & & Small & Medium & Large & $P$ & Urban & Rural & $\begin{array}{l}\text { OR }(95 \% \mathrm{Cl}) \text { raw } \\
\text { (unadjusted)* }\end{array}$ & $\mathrm{p}$ & $\begin{array}{c}\text { OR } \\
(95 \% \mathrm{Cl}) \\
\text { adjusted by school size * }\end{array}$ & $P$ \\
\hline Indoor gym & 94.8 & 72.7 & 98.1 & 100.0 & $<0.001$ & 98.9 & 86.4 & $\begin{array}{c}14.21 \\
(1.65-122.08)\end{array}$ & 0.016 & $\begin{array}{c}2.72 \\
(0.27-27.15)\end{array}$ & NS \\
\hline also outside school lessons & 70.7 & 45.5 & 79.6 & 71.9 & 0.012 & 73.0 & 65.9 & $\begin{array}{c}1.40 \\
(0.64-3.06)\end{array}$ & NS & $\begin{array}{c}1.05 \\
(0.356-3.05)\end{array}$ & NS \\
\hline Outdoor playground areas & 95.5 & 95.5 & 94.3 & 96.6 & NS & 92.3 & 95.5 & $\begin{array}{c}0.57 \\
(0.11-2.87)\end{array}$ & NS & $\begin{array}{c}0.31 \\
(0.05-1.77)\end{array}$ & NS \\
\hline also outside school lessons & 93.3 & 95.5 & 88.9 & 96.6 & NS & 96.7 & 93.2 & $\begin{array}{c}2.12 \\
(0.41-10.97) \\
\end{array}$ & NS & $\begin{array}{c}2.32 \\
(0.25-21.16 \\
\end{array}$ & NS \\
\hline $\begin{array}{l}\text { Organised sports classes, outside } \\
\text { school lessons (once a week or } \\
\text { more often) }\end{array}$ & 66.4 & 63.6 & 61.1 & 72.4 & NS & 68.9 & 61.4 & $\begin{array}{c}1.39 \\
(0.66-2.96)\end{array}$ & NS & $\begin{array}{c}1.11 \\
(0.43-2.85)\end{array}$ & NS \\
\hline Canteen & 90.4 & 72.7 & 88.9 & 98.3 & 0.002 & 96.7 & 77.3 & $\begin{array}{c}8.63 \\
(2.24-33.27)\end{array}$ & 0.002 & $\begin{array}{c}3.71 \\
(0.76-18.24)\end{array}$ & NS \\
\hline Shop/cafeteria & 39.1 & 13.6 & 34.0 & 53.4 & 0.003 & 46.1 & 25.0 & $\begin{array}{c}2.56 \\
(1.15-5.70) \\
\end{array}$ & 0.021 & $\begin{array}{c}1.20 \\
(0.43-3.34) \\
\end{array}$ & NS \\
\hline $\begin{array}{l}\text { Food vending machine (other than } \\
\text { water, fruit/vegetables) }\end{array}$ & 20.1 & 13.6 & 22.2 & 20.7 & NS & 22.2 & 15.9 & $\begin{array}{c}1.51 \\
(0.56-3.90)\end{array}$ & NS & $\begin{array}{c}1.60 \\
(0.49-4.92\end{array}$ & NS \\
\hline $\begin{array}{l}\text { Marketing of energy-dense } \\
\text { products }\end{array}$ & 6.7 & 4.5 & 5.6 & 8.6 & NS & 5.6 & 9.1 & $\begin{array}{c}0.59 \\
(0.15-2.31)\end{array}$ & NS & $\begin{array}{c}0.12 \\
(0.01-1.58)\end{array}$ & NS \\
\hline
\end{tabular}

* Reference category: rural school

Table 3. Availability of selected foods to pupils within school premises and their association with school size and location ( $\mathrm{N}=135$ schools)

\begin{tabular}{|c|c|c|c|c|c|c|c|c|c|c|c|}
\hline \multirow[b]{2}{*}{ Type of product } & \multirow[b]{2}{*}{ Total } & \multicolumn{4}{|c|}{ School size } & \multicolumn{2}{|c|}{ School location } & \multicolumn{4}{|c|}{ Result of logistic regression } \\
\hline & & Small & Medium & Large & $\mathrm{P}$ & Urban & Rural & OR $(95 \% \mathrm{Cl})$ raw & $\mathrm{p}$ & $\begin{array}{l}\text { OR }(95 \% \mathrm{Cl}) \text { adjusted } \\
\text { by school size }\end{array}$ & $P$ \\
\hline Vegetables & 93.8 & 90.9 & 96.2 & 92.9 & NS & 92.0 & 97.6 & $0.28(0.03-2.37)$ & NS & $\begin{array}{c}0.14 \\
(0.01-1.72)\end{array}$ & NS \\
\hline Milk, yoghurt & 88.4 & 77.3 & 92.2 & 89.3 & NS & 88.5 & 88.1 & $1.04(0.33-3.26)$ & NS & $\begin{array}{c}0.60 \\
(0.13-2.74)\end{array}$ & NS \\
\hline Fruit juices without added sugar & 54.7 & 31.6 & 50.0 & 67.3 & 0.020 & 55.6 & 52.8 & $1.12(0.51-2.46)$ & NS & $\begin{array}{c}0.40 \\
(0.14-1.14)\end{array}$ & NS \\
\hline Fruit juices with added sugar & 39.3 & 38.9 & 34.8 & 43.4 & NS & 40.2 & 37.1 & $1.14(0.50-2.57)$ & NS & $\begin{array}{c}0.97 \\
(0.35-2.72)\end{array}$ & NS \\
\hline Flavoured milk with added sugar & 23.7 & 31.6 & 26.5 & 18.0 & NS & 16.5 & 38.5 & $0.32(0.13-0.76)$ & 0.010 & $\begin{array}{c}0.27 \\
(0.08-0.89)\end{array}$ & 0.031 \\
\hline Sweet carbonated drinks & 5.9 & 5.6 & 6.1 & 5.8 & NS & 6.1 & 5.4 & $1.14(0.21-6.15)$ & NS & $\begin{array}{c}1.22 \\
(0.15-9.62)\end{array}$ & NS \\
\hline $\begin{array}{l}\text { Sweet snacks (biscuits, candy } \\
\text { bars, chocolate) }\end{array}$ & 34.8 & 11.8 & 30.4 & 46.2 & 0.026 & 39.5 & 23.5 & $2.12(0.86-5.27)$ & NS & $\begin{array}{c}1.03 \\
(0.33-3.11)\end{array}$ & NS \\
\hline $\begin{array}{l}\text { Savoury snacks (crisps, salted } \\
\text { nuts) }\end{array}$ & 6.9 & 0.0 & 8.3 & 8.0 & NS & 8.8 & 2.8 & $\begin{array}{c}3.36 \\
(0.40-28.35)\end{array}$ & NS & $\begin{array}{c}2.62 \\
(0.26-26.45)\end{array}$ & NS \\
\hline
\end{tabular}

Assessment of school nutrition environment. School canteens existed in the majority of the analysed schools (90\%), significantly more often in urban than in rural schools, and in large schools compared to small and medium schools. Urban schools, as well as large schools regardless of their location, significantly more often had shops and cafeterias. Vending machines offering products other than water, fruit and vegetables, were available at every $5^{\text {th }}$ school, more often in urban than rural schools, and more often in large and medium schools than in small schools (statistically non-significant differences (Tab. 2). In approximately $70 \%$ of schools, there was advertising of energy-dense and nutrient-poor foods, more often in rural schools and in large schools. 
Table 3 presents the percentages of schools with available selected foods and beverages. Healthy foods, i.e. fruit and vegetables, were available to pupils in over $90 \%$ of schools, and milk and yoghurts in over $80 \%$ of schools. Water was available in $85 \%$ of schools, significantly less often in small schools $(\mathrm{p}=0.016)$.

Foods and beverages with a rather unfavourable impact on the children's health which were available in the analysed schools included fruit juices with added sugar, sweet snacks (sweet biscuits, candy bars, candies, etc.) in over one-third of schools, and flavoured milk with added sugar in every $4^{\text {th }}$ school. Significant differences were found in the availability of those products depending on school location and size. Large schools and urban schools were characterised by a greater availability of sweet snacks ( $p=$ 0.026). In approximately $6 \%$ of the analysed schools, such products as sweet carbonated drinks were available, similarly in urban and rural schools, and savoury snacks (e.g. crisps) more often in urban schools.

Univariate logistic analysis parameters, calculated for all analysed variables describing the school nutrition environment, showed that the urban-rural school location had a significant association in the school, within a canteen $\mathrm{OR}=8.63(2.24-33.27 ; \mathrm{p}=0.002)$, a shop/cafeteria $\mathrm{OR}=2.56$ $(1.15-5.70 ; \mathrm{p}=0.021)$ and availability of flavoured milk with added sugar $\mathrm{OR}=0.32(0.13-0.76 ; \mathrm{p}=0.010)$. After entering the school size variable to the regression model, school location remained significant only in the case of availability of flavoured milk.
School physical activity and nutrition environment assessment index. The distribution of the school environment index values in individual schools is presented in Figure 1. The most often occurring value of the index (mode) is 16.0 points, and concerned almost one-fourth of the schools (23.2\%), including 20\% urban and 30\% rural schools.

The average result of the index for all schools was 16.07 $(\mathrm{SD}=1.9)$ points (Tab. 4). Statistically significant differences in mean index values were found, depending on the school size $(\mathrm{p}<0.001)$. The index was the highest for large schools, and the lowest for small schools (Tab. 4). There were no statistically significant differences between urban and rural schools.

Table 4. Mean result and standard deviation of school physical activity and nutrition environment assessment index, depending on school size and location

\begin{tabular}{lcccc}
\hline Schools & Mode & Mean & Standard deviation & P \\
\hline Total & 16.00 & 16.07 & 1.86 & \\
\hline Size & & & & \\
\hline small & 14.00 & 14.33 & $<.13$ & $<001^{\text {a }}$ \\
\hline medium & 16.00 & 16.06 & 1.58 & \\
\hline large & 17.00 & 16.85 & 1.48 & \\
\hline Location & & & & NS $^{\text {b }}$ \\
\hline urban & 16.00 & 16.25 & 1.80 & 2.0 \\
\hline rural & 16.00 & 15.70 & & \\
\hline
\end{tabular}

${ }^{a}$ Based on Kruskal-Wallis test

${ }^{\mathrm{b}}$ Based on U-Mann Whitney test

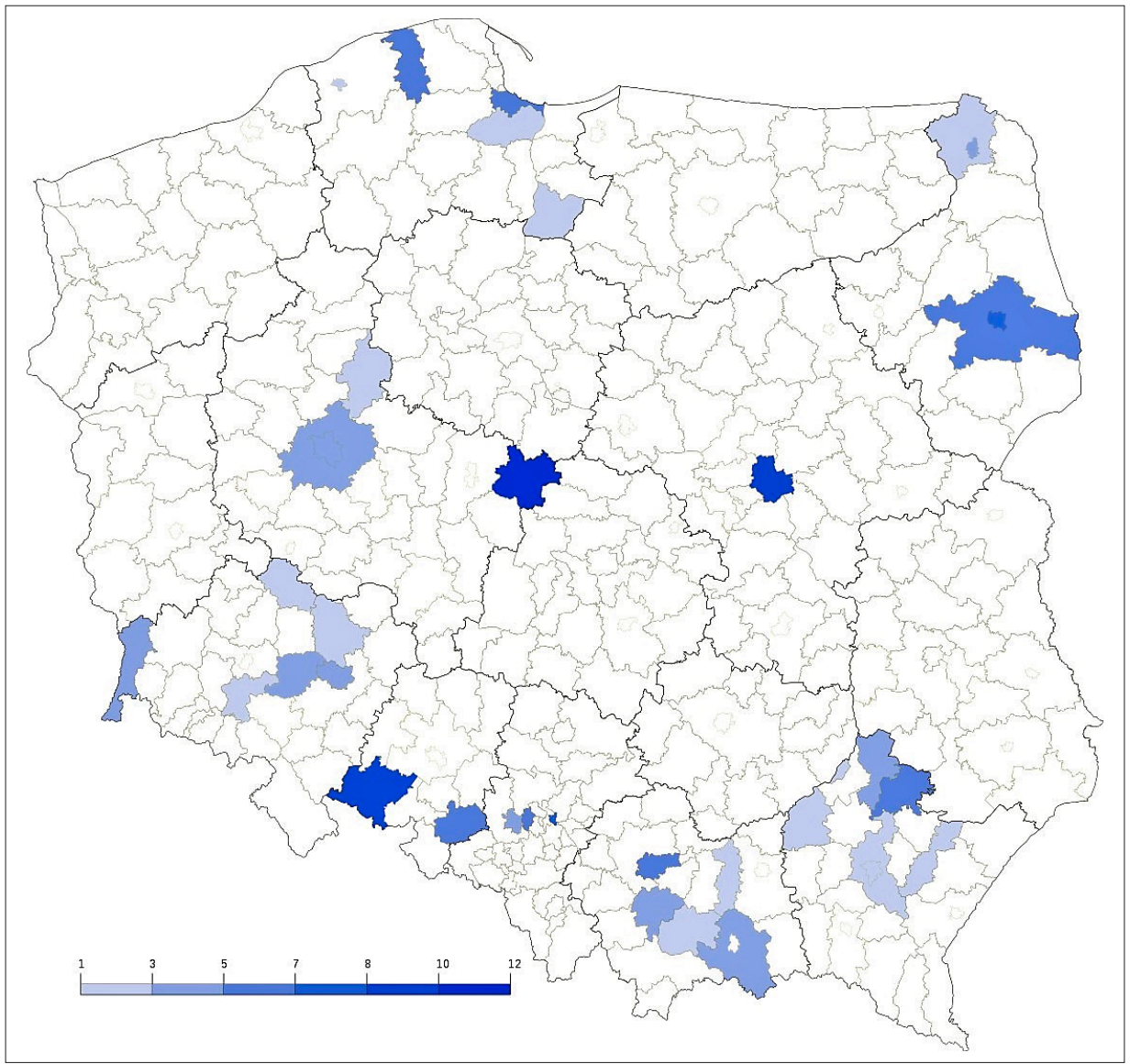

Figure 1. Territorial distribution of schools participating in the COSI POLAND survey, by poviats $(\mathrm{N}=135)-$ different shades of colour mean the number of schools in the poviats 


\section{DISCUSSION}

The presented study is the first to be published in Poland which takes into account not only the school location, but also the school size measured by the number of pupils, in the assessment of the school physical activity and nutrition environment.

In the work methodology, a questionnaire survey conducted among school employees was used. This is currently a commonly applied method of collecting data on various aspects of the functioning of the education environment with respect to conditions conducive to health, development and welfare of the pupils. The majority of studies on conditions conducive to physical activity in the school environment do not measure objectively the environment parameters, but are comprised of questionnaire surveys conducted among school employees [18] or pupils [3, 19]. In one of very few studies which include objective measurements, Webber et al. conducted an environmental audit, but it was used as the basis for evaluating schools as workplaces, analysing how the school environment characteristics influence the physical activity of their personnel, not the pupils [20].

The results of other Polish studies on the impact of the school environment on the healthy lifestyle of pupils allow the conclusion that such factors as physical/construction condition of the buildings and their furnishing (indoor gym, outdoor playing area, canteen), as well as the principles of the school policy on healthy eating and physical activity promotion, are additional elements differentiating schools with respect to the environment beneficial for the pupils' health $[21,22]$.

Evidence from systemic reviews, which mostly include studies carried out in the USA, shows that school nutrition strategies (including school canteens and shops) are efficient in the process of decision-making during shopping and in the improvement of nutritional behaviour of children. The opinions show that an increased availability of healthy options, reduction of the sale of unhealthy foods, and competitive prices of healthy food products, increased the consumption of vegetables and fruits among children and reduced the consumption of saturated fats at school [23]. The authors also emphasize the role of federal, state and local policies on food standards and physical activity in schools [24].

In the international arena, the school nutrition environment is diversified. Some countries, including the United States, the United Kingdom and France, provide meals as part of school lunch programmes, while others, such as Australia, Canada, New Zealand, and the Netherlands, provide food and beverages available to everyone in school shops or canteens $[25,26]$.

In Poland, the current amendment to the education law includes provisions ensuring that from 1 September 2021 all pupils attending primary schools will have the possibility to have a hot meal at school. Schools and local governments will have an obligation to establish dining rooms (from 2019) and school canteens (from 2021). In addition, the amendment to the Regulation of the Ministry of National Education of 31 December 2002 on health and safety conditions in public and non-public schools and establishments (Journal of Laws [Dz. U.] 2003, No, 6, item 69), will impose an obligation on schools to organise a break between lessons that will allow consumption of a meal.
Increasing time for the school lunch period from the standard 20 minutes to a longer 30-minutes period, and scheduling recess before school lunch, have both been found to increase the consumption fruit and vegetables [27].

The initial hypothesis of the presented study assumed that school location in rural or urban areas would be a factor differentiating the school environment elements related to physical activity and nutrition. In rural areas, where social resources for healthy eating and physical activity are limited, schools perform an important role in obesity prevention [28]. Conversely, research shows that rural children achieve a low level of physical activity at school and that it is inversely proportional to their body mass index [29].

In the current study, the assessment of the school physical activity environment found no differences in access to school outdoor playing areas depending on school location, and no differences in the weekly duration of physical education classes. However, there were statistically significant differences in the number of physical education lessons depending on the school size. The weekly number of physical education lessons amounting to 3 or more was least often achieved by small schools. Statistically significant differences were found in access to indoor gyms; however, after the introduction of the school size category variable to the logistic regression model, the urban-rural school location proved to be no longer significant.

Analysis of the school nutrition environment included the calculation of parameters for all variables of infrastructure and accessibility in the univariate logistic regression analysis. They showed that the urban-rural school location had a significant association in the case of availability of a canteen, shop/cafeteria in the school (to the disadvantage of rural schools) and availability of flavoured milk (significantly more often in rural areas). This unexpected association is difficult to explain. Perhaps it was caused by a greater interest of parents of rural children in the availability of flavoured milk in the last year of the programme "Milk at School" - the children drank milk more willingly and the parents considered it more "healthy" (in particular the chocolate variety) [30]. Currently, from the 2018-2019 school year, the Programme for Schools no longer offers flavoured milk or yoghurt with added sugar [31].

In Australian studies, large schools had considerably higher opportunities to have a healthy menu, and medium schools had higher opportunities to have a policy on canteens and healthy nutrition than small schools. The policy covered the setting of prices, promotion and availability of healthy foods [32].

Assessment of the mean school physical activity and nutrition environment index also revealed that the highest values were recorded in large schools and the lowest in small schools. School location was also not a differentiating variable in this case.

Due to the decrease in the birth rate, persistent for many years, the school became a place of dynamic quantitative changes. In numerous regions of Poland and Europe, small schools become the main elements of the school network structure. This topic is practically non-existent in scientific considerations, while the analysis of demographic forecasts shows that the changes will be one of important factors defining the direction of development of the Polish school system [33].

One of the most frequently formulated stereotypes in relation to small schools is the "unprofitability" of their 
functioning, since the cost of education at those schools is considerably higher than in large schools. This results in the lack of actions aimed at developing their infrastructure, and often even in their liquidation. However, small school communities are characterised by stable social relations, providing an opportunity for teachers and pupils to create, among others, original education programmes, including health promotion and health education. The studies by American authors also showed that pupils in small schools more often had participated in activities organised by the school and local community than their peers in large schools, although large schools usually offered more activities [34].

According to Pęczkowski, a small school with the abovepresented characteristics seems to be an ideal place for promoting the initiatives supporting the development of children [33]. However, this requires action on the part of all participants of the education processes, as well as a change in the organisation of small school functioning.

Strengths of the study. Considering the small number of publications on the subject, this is the first scientific study of this type in Poland. It introduces the subject of school physical activity and the nutrition environment. In addition, it identifies the problem of small schools in which, because of their poor infrastructure, students lack adequate support in the field of proper nutrition and physical activity.

Limitations of the study. Assessment of the school environment with respect to supporting appropriate nutrition and physical activity of pupils did not take organisational factors into account, in particular those concerning nutrition (e.g. a break for the main meal and its duration, food preparation, consumption of elevenses together, involvement of teachers and school employees) [4].

The school survey questionnaire, prepared according to the COSI protocol, included only questions concerning infrastructure and availability, while the organisational questions concerned only sport activities outside school hours. School-based healthy lifestyle programmes need to be integrated within the curriculum and long-term school policies, with sustained support from head teachers and staff, and with the involvement of parents [35].

\section{CONCLUSIONS}

1. The factor which adversely differentiates the school environment in terms of healthy nutrition and physical activity, primarily is the school size, followed by the school location.

2. Assessment is the first step in identifying opportunities for improvement and starting a planning process for making schools even healthier. Systemic and social solutions should aim at reducing the small school "exclusion syndrome", both in rural and in urban areas, also with regard to infrastructure and availability of conditions conducive to healthy nutrition and physical activity.

\section{REFERENCES}

1. Pate RR, Davis MG, Thomas Robinson TN, Stone EJ, McKenzie TL, Young JC. Promoting Physical Activity in Children and Youth. A
Leadership Role for Schools. A Scientific Statement from the American Heart Association Council on Nutrition, Physical Activity, and Metabolism (Physical Activity Committee) in Collaboration with the Councils on Cardiovascular Disease in the Young and Cardiovascular Nursing. Circulation 2006; 114: 1214-1224. https://doi.org/10.1161/ CIRCULATIONAHA.106.177052

2. Physical Activity Guidelines for Americans. $2^{\text {nd }}$ edition. Department of Health and Human Services. Washington, DC: U.S; 2018. https://health. gov/paguidelines/second-edition/pdf/Physical_Activity_(access: 2019.09.23).

3. Haug E, Torbjørn T, Samdal O. Physical environmental characteristics and individual interests as correlates of physical activity in Norwegian secondary schools: the health behaviour in school-aged children study. IJBNPA 2008; 5: 47-56.

4. Lien N, van Stralen MM, Androutsos O, Bere E, Fernandez-Alvira JM, Jan N, et al. The school nutrition environment and its association with soft drink intakes in seven countries across Europe - the ENERGY project. Health Place 2014; 30: 28-35.

5. French SA. Public health strategies for dietary change: schools and workplaces. J Nutr. 2005; 135(4): 910-912.

6. Story M, Kaphingst KM, Robinson-O’Brien R, Glanz K. Creating healthy food and eating environments: policy and environmental approaches. Annu Rev Public Health. 2008; 29: 253-72.

7. Vaitkevi ${ }^{`}$ ciute J, Aušra Petrauskienè. The Associations between Body Mass Index of Seven-and Eight-Year-Old Children, Dietary Behaviour and Nutrition-Related Parenting Practices. Medicina 2019, 55, 24; doi: 10.3390/medicina55010024.

8. Bazzano LA. Dietary intake of fruit and vegetables and risk of diabetes mellitus and cardiovascular diseases. WHO; 2005: 22-32. http://www. who.int/dietphysicalactivity/publications/f\%26v_cvd_diabetes.pdf (access: 2019.08.24).

9. Rolls BJ, Ello-Martin JA, Tohill BC. What can intervention studies tell us about the relationship between fruit and vegetable consumption and weight management? Nutr Rev 2004; 62: 1-17.

10. A tool for the development of school nutrition programmes in the European Region Programme for Nutrition and Food Security WHO Regional Office for Europe Copenhagen 2006.

11. Regulation of the Minister of Health of 26 August 2015 regarding of groups of food products intended for sale to children and adolescents in educational system institutions and the requirements which food products used as part of mass nutrition for children and adolescents must meet. (J. L. item. 1256).

12. Regulation of the Minister of Health of 26 July 2016 regarding of groups of food products intended for sale to children and adolescents in educational system institutions and the requirements which food products used as part of mass nutrition for children and adolescents must meet. (J. L. item. 1154).

13. Fijałkowska A, Oblacińska A, Stalmach M. Overweight and obesity in Polish 8-year-olds in the light of biological, behavioral and social conditions. Report on international WHO research European Childhood Obesity Surveillance Initiative (COSI). Institute of Mother and Child, Warsaw 2017.

14. Comprehensive Framework for Addressing the School Nutrition Environment and Services. Revised February 2019. Centers for Disease Control and Prevention. National Center for Chronic Disease Prevention and Health Promotion. https://www.cdc.gov/healthyschools/nutrition/ pdf

15. Sallis JF. Measuring Physical Activity Environment. A Brief Story. Am J Prev Med 2009; 36(4): S86-92.

16. Childhood Obesity Surveillance Initiative (COSI), Protocol, October 2016, World Health Organization 2017. http://www.euro.who.int/data/ assets/pdf_file/0018/333900/COSI-protocol-en.pdf

17. Regulation of the Minister of National Education of 9 August 2011 regarding acceptable forms of implementation of mandatory physical education classes. (J. L. No. 175, item. 1042).

18. Young DR, Felton GM, Grieser M, Elder JP, Johnson C, Lee JS, et al. Policies and opportunities for physical activity in middle school environments. Journal of School Health 2007; 77: 4104.

19. Robertson-Wilson J, Levesque L, Holden RR. Development of a questionnaire assessing school activity environment. Measurement in Physical Education and Exercise Science 2007; 11: 93-107.

20. Webber LS, Johnson CC, Rose D, Rice JC. Development of ACTIONI Wellness program for elementary school personnel. Obesity 2007; 15(suppl 1): 48S-56S.

21. Woynarowska B. Nutrition and healthy eating policy in healthpromoting schools in Poland. Hygeia Public Health 2014, 49(3): 490-494. 
22. Woynarowska B, Komosińska K, Małkowska-Szkutnik A. Physical environment of primary and junior high schools in Poland as assessed by their headmasters. Probl Hig Epidemiol. 2011; 92(3): 455-460.

23. Driessen CE, Cameron AJ, Thorton LE, Lai SK, Barnett LM. Effect of changes to the school food environment on eating behaviours and/or body weight in children: a systematic review. Obes Rev. 2014; 15(12) 968-982.

24. Story M, Nanney MS, Schwartz B. Schools and Obesity Prevention: Creating School Environments and Polices to Promote Healthy Eating and Physical Activity. The Milbank Quarterly, 2009; 87(1): 71-100.

25. Harper C, Wood L, Mitchel C. The provision of School Food in 18 Countries. London: School Food Trust, 2008.

26. Menksink F, Antoinette Schwinghamme S, Smeets A. The Healthy School Canteen programme: a promising intervention to make the school food environment healthier. J Environ Public Health 2012; ID 415746

27. Ang IYH, Wolf RL, Koch PA, Gray HL,Trent R, Tipton E, et al School Lunch Environment Factors Impacting Fruit and vegetable Consumption. J Nutr Educ Behav 2019; 51(1): 68-79.

28. Hatfield DP, Chomitz VR. Increasing Children's Physical Activity During the School Day. Curr Obes Rep. 2015; 4(2): 147-56.

29. Gunter KB, Nader PA, John DH. Physical activity levels and obesity status of Oregon Rural Elementary School children. Prev Med Rep. 2015; $2: 478-82$
30. Members' parliamentary exception - response of the Minister of Agriculture to the program "Milk for Schools" http://orka2.sejm.gov.pl/ INT8.nsf/klucz/658C47F1/\%24FILE/i18442-ol.pdf(access: 2019.08.24).

31. Regulation of the Minister of Agriculture and Rural Development of 11 July 2018 on the detailed scope of tasks implemented by the National Center for Agricultural Support with the implementation of a school program on the territory of the Republic of Poland (J. L. 2018; item 1468)

32. Yoong SE, Nathan NK, Wyse RJ, Preece SJ, Williams CM, Sutherland RL, et al. Assessment of the School Nutrition Environment. A Study in Australian Primary School Canteens. Am J Prev Med. 2015; 49(2): 215-222.

33. Pęczkowski R. Small schools in the education system - the necessity, problem or opportunity, in: Mayerová K, editor. Education and Social Stratification, Prešovská University, Slovakia; 2014.

34. Duke DL, DeRoberto T, Trautvetter S. Reducing the Negative Effects of Large Schools. In: National Clearinghouse for Educational Facilities Washington, DC; 2009. https://eric.ed.gov/?id=ED507894 (access: 2019.08.24).

35. Day RE, Sahota P, Christian MS. Effective implementation on primary school-based healthy lifestyle programmes: a quality study of views of school staff. BMC Public Health 2019;19(1):1239. doi: 10.1186/S12889019-7550-2. 